\title{
A Phenomenological Investigation of Leader Development and Mindfulness Meditation
}

\author{
Denise A. Frizzell \\ Walden University \\ Stephanie Hoon \\ Walden University \\ David K. Banner \\ Walden University
}

\begin{abstract}
Regardless of the gap between the demands of the global work environment and the maturity of leaders, minimal research exists on the trend of the practice of mindfulness meditation and the developmental experiences of leaders. Consequently, scholars have little understanding of how an increasing number of leaders experience mindfulness meditation. The purpose of this study was to understand the perceived impact mindfulness meditation had on leader development for 20 manager-leaders who had a regular (at least 3 days a week) mindfulness meditation practice. The primary recruitment strategy included outreach to potential participants affiliated with professionally oriented mindfulness groups on LinkedIn. The main conceptual framework was Day's conceptualization of leader development. The central research question addressed leaders' perceptions and experiences of the impact of mindfulness meditation on their development as leaders. A modified Stevick-Colaizzi-Keen data analysis procedure was used in this study. Key results included the identification of 10 core themes and the associated conclusion that leaders who want to contribute solutions to global challenges will have to access more of their potential, which may require engaging in contemplative practices such as mindfulness meditation. The principal recommendation includes the serious consideration of mindfulness meditation by leaders and organizational decision makers of development investments. This study has implications for positive social change, in that a better understanding of how leaders experience mindfulness meditation may provide direction for leaders and organizations about developmental practices that support leadership effectiveness.
\end{abstract}

Keywords: leadership, leader development, mindfulness meditation, vertical development

\section{Introduction}

Meditation is growing in popularity in the United States, both in the general population and with business leaders (Gelles, 2015; Rauzi, 2013). Historically, the family of meditation techniques falls into two general categories: concentration and receptive (Goleman, 1988). Mindfulness meditation, a receptive practice, has roots in Buddhism and typically refers to practices that bring gentle, unbiased attention and awareness to the moment (Shapiro, Carlson, \& Kabat-Zinn, 2009). 
However, many Western mindfulness-based interventions (MBIs) are secular and accessible to diverse populations (Shapiro et al., 2009). Tan (2012) explained Google's commitment to offer mindfulness training to employees throughout the company to support them "succeed in life and work" (p. 3). Nevertheless, scholarship has not yet caught up with this emerging trend of leaders increasing use of mindfulness meditation and MBIs.

\section{Background}

A gap exists between the demands of the global work environment and the developmental maturity of its leaders. As highlighted by Weiss and Molinaro (2010), this developmental gap makes leaders and the organizations they lead vulnerable to costly missteps and performance declines. The global work environment places increasing demands on leaders who are ill prepared to address these demands effectively (Baron \& Cayer, 2011; Weiss \& Molinaro, 2010). Bird, Mendenhall, Stevens, and Oddou (2010) reported more than 50 competencies associated with global leadership effectiveness, which they organized into three comprehensive categories: perception management, relationship management, and self-management. As presented in the Literature on Leader Development section, mindfulness scholars have indicated positive correlations between these three comprehensive categories and MBIs.

With few exceptions (e.g., the Leadership Circle Profile), prevailing leader development best practices (e.g., $360^{\circ}$ feedback or multisource feedback) fall short of meeting the need to develop 21stcentury leaders. This shortcoming is due in part to a lack of attention to the inner worlds from which leaders lead, including psychological and emotional maturity (Ruderman, Clerkin, Connolly, \& Center for Creative Leadership, 2014). Therefore, practitioners and scholars may need to shift more attention to cultivating intrapersonal maturity and not solely knowledge and skills.

To address this developmental void, leaders and businesses are turning to mindfulness meditation and MBIs. Researchers have indicated the benefits of MBIs for general self-development, including the cultivation of psychological maturity and competencies associated with leader effectiveness (Brown, Ryan, \& Creswell, 2007; Gelles, 2015; Siegel, 2014). However, currently, MBIs have received negligible attention in the leadership development literature, thereby leaving a division between theory and practice to include the lack of understanding of the developmental experiences leaders have of MBIs.

\section{Literature on Leader Development}

The primary conceptual framework was Day's (2001) conceptualization of leader development. Day defined leader development as the capacity of individuals to fulfill leadership roles, responsibilities, and tasks successfully, while emphasizing development of knowledge, skills, and capacities related to effective leadership. Day emphasized the distinctions between leader development and leadership development.

Leader development refers to individual-based knowledge, skills, abilities, and character connected to formal leadership responsibilities, and leadership development is concerned with cultivating interpersonal knowledge, skills, abilities (Day, 2001). Furthermore, Day, Harrison, and Halpin (2012) argued that the relationship between leader and adult development is instrumental to any meaningful theory of leader development. Consequently, an integrative approach to leader development, grounded in adult development theory, would benefit leaders. 
At least two fundamental assumptions underlie the leader development literature. Individuals can grow and transform, and people will do so if they have adequate resources and training (Anderson \& Ackerman-Anderson, 2010). These assumptions are significant to the leader development literature because they provide organizational decision makers with a rationale for investing in growthoriented activities. In addition, these assumptions may inspire individual leaders to seek growth opportunities inside and outside the organization.

The leader competency model represents a dominate conceptualization of leader development (Ruderman et al., 2014; Vazirani, 2010). The concept of competency refers to an ability or capacity necessary for role effectiveness (Boyatzis as cited by Bolden \& Gosling, 2006). In practice, a growing number of organizations have some type of framework that identifies competencies needed for effective leadership (Ruderman et al., 2014; Vazirani, 2010). The competency movement has roots in the work of McClelland (1973), the work of the McBer consultancy firm in the 1970s, and the work of Boyatzis (all as cited in Bolden \& Gosling, 2006).

Currently, three predominant threads in the leader development literature include the leader's developmental journey, development interventions, and organizational best practices. For the purposes of this article, the focus is on aspects of the leader's developmental journey. Bennis (2009) wrote, "The process of becoming a leader is much the same as becoming an integrated human being" (p. xxxii). Thus, many factors shape leader development including work and life experiences (McCall, 2010).

\section{Work and Career}

Leadership capacities grow more through work experiences than solely formal training. Scholars generally categorize developmental experiences as superior relationships, early career experiences, short-term assignments, challenging assignments, various types of hardships, and various events, such as training programs (McCall, 2010). Furthermore, leaders optimize developmental experiences by (a) using personal motivation and achievement orientation to maximize early life and career experiences; (b) cultivating personal strategies to acquire life balance; (c) committing to selfawareness and self-regulation; (d) acknowledging that a person cannot work alone, but must honor his/her individual strengths; and (e) adjusting a leadership style as required, while remaining true to values and principles (McDermott, Kidney, \& Flood, 2011). Consequently, leader development results from a dynamic interplay between work and life experiences.

\section{Life}

Life offers countless opportunities for growth, including in the area of leader development. Evidence strongly indicates that growth experiences and the mental models that result are highly significant and demand attention from scholars and practitioners (Ligon \& Hunter, 2010). In addition, childhood experiences (e.g., sports) may provide the seeds for future leadership qualities to grow (Murphy \& Johnson, 2011). Life experiences that demand new ways of seeing oneself and one's relationship with others and the larger world hold the most potential for learning.

From this view, the purpose of leadership education is to facilitate experiences that challenge existing ways of seeing. This approach necessitates that leaders reinterpret and make sense of life experiences toward more meaningful life narratives that support and accelerate leaders' development (Petriglieri, Wood, \& Petriglieri, 2011). Accordingly, reflection and integration are essential elements of learning leadership from challenging experiences to foster greater self- and social awareness (Ligon \& Hunter, 2010). However, anxiety and self-doubt, and the associated selfsabotaging actions that may occur, often arise from maladaptive interpretations of life experiences 
and may deter authentic engagement in growth-oriented experiences (Avolio \& Hannah, 2008). Life experiences are clearly a critical element of leader development and fertile ground for additional inquiry.

The development of leaders, directly related to sustainable success, is one of the most important development functions of an organization (Goldman Schuyler, 2010). However, most organizations have yet to master the art and science of leader development. Therefore, senior staff must remain open to emerging trends that might enhance mastery of leader development (Goldman Schuyler, 2010). Related emerging trends in the leader development literature include focus on leader development as vertical development and innovative leader-development methods (e.g., Petrie, 2014, 2015; Roche, Haar, \& Luthans, 2014; Ruderman et al., 2014).

\section{Vertical Development}

Petrie (2011) proposed that adult-development theory might help illuminate one of the underlying causes of competency-model fatigue: the failure to discern between horizontal and vertical development. Horizontal development is the development of instrumental learning and most advantageous when the problem and known solutions are straightforward. In contrast, vertical development refers to structural shifts in developmental intelligences that result in fresh and more inclusive perspectives about the self, others, nature, and the Source of all life.

Leaders experience growing pressure to handle complexity, collaborate with diverse populations, and accept responsibility for their development (Weiss \& Molinaro, 2010). Furthermore, 21st-century demands place increasing pressures on today's leaders to relinquish limiting identities and form more inclusive identities (Kegan \& Lahey, 2009). Greater intrapersonal intelligence typically includes growing capacity to comprehend more complexity, which naturally involves a transition toward a more inclusive self-identity.

However, the majority of organizational manager-leaders have not yet reached this stage of maturity (Joiner \& Josephs, 2007; Torbert \& Cook-Greuter, 2004). Furthermore, today's popular leader development interventions fall short of producing the type of change required (Hezlett, 2008). Consequently, Petriglieri et al. (2011) highlighted growing curiosity about andragogical approaches that extend into the domain of intrapersonal intelligence by encouraging deeper reflection on how leaders' pasts shape their current identity, perceptions, interpretations, and behavior. Similarly, Ruderman et al. (2014) urged experimentation and innovation in approaches to leader development.

\section{Innovative Leader-Development Methods}

Given the challenges and opportunities organizations face to develop leaders prepared for the 21st century, organizations and leaders must remain open to innovative leader-development methods while gleaning the wisdom provided by best-practice literature. Day et al. (2012) declared leaderdevelopment theory must include aspects such as identity formation, self-awareness, mental models, critical thinking, and technical skills. Innovative recommendations to leader development include a growing body of scholars urging consideration of various types of meditation techniques for leader development (e.g., Petrie, 2015; Roche et al., 2014; Ruderman et al., 2014).

Mindfulness meditation and MBIs, as previously highlighted, are growing in popularity in the United States among business leaders (Gelles, 2015; Rauzi, 2013). MBIs repeatedly demonstrate positive physiological and psychological outcomes (Siegel, 2014). For example, Kemeny et al. (2012) determined that an intensive 8-week investigation of a MBI modified emotional and mental states 
and traits related to individual well-being and social solidarity. The authors determined that the MBI also held potential to enhance positive mental states and prosocial behaviors.

Although one might dismiss mindfulness as the latest fad in organizational development, the mounting body of scientific literature, indicating impressive benefits for clinical and healthy populations, challenges such a position (Glomb, Duffy, Bono, \& Yang, 2011). As Kabat-Zinn (1994) wrote, "Meditation is really about human development" (p. 81), whereas Day et al. (2012) declared that having a solid foundation in human development is essential to understand and intervene in leader development. However, currently, while practitioners garner increased interest in mindfulness meditation and leader development, scholars conduct few studies on this topic.

\section{Mindfulness Meditation and Leader Development}

Mindfulness meditation allows a leader to appreciate the changing nature of reality and begin to relinquish over-identification with particular views or outcomes (Gelles, 2015). Mindful leaders tend to have stronger intrapersonal and interpersonal skills; therefore, they frequently become more effective in fulfilling their leadership responsibilities and functions (Boyatzis \& McKee, 2013). Consequently, Ruderman et al. (2014) concluded that mindfulness offers leaders techniques to interrupt habitual thoughts and reactionary patterns while creating opportunities for reperceiving and responding in ways that are more constructive. However, as Baron and Cayer (2011) cautioned, the practice of mindfulness is far from an instant remedy. Similarly, Goldman Schuyler (2010) warned that cultivating mindfulness is comparable to starting an exercise program rather than learning a particular management skill, which may explain its underrepresentation in the leaderdevelopment literature.

\section{Method}

The purpose of this study was to understand the perceived impact mindfulness meditation had on leader development for 20 manager-leaders who had a regular (at least 3 days a week) practice for at least 3 months. The sampling population for this exploration consisted of adults who served as organizational leaders - middle and senior managers-who had a regular mindfulness practice. The data collection instrument used for this inquiry was in-depth, open-ended interviews: one extended interview session per participant.

Responses to interview questions illuminated the central research question: How do leaders perceive and describe their experiences of the impact of mindfulness meditation on their development as leaders? We used a modified Stevick-Colaizzi-Keen method of analysis (see Moustakas, 1994) for phenomenological data. Twenty-one manager-leaders engaged in single in-depth interviews. After initial, brief telephone meetings, we conducted interviews either in-person (one session), by telephone (two sessions), or via the Internet (Skype, 16 sessions and GoToMeeting, one session). The duration of the interviews ranged from 35 to $60 \mathrm{~min}$.

\section{Results}

From 20 verbatim transcripts, approximately 404 significant statements were extracted, which resulted in 15 working themes. Analyzing themes for unique theme representation and words dedicated to each theme resulted in 10 final themes (see Table 1). Themes with 10 or fewer total unique participants were dropped from further analysis. For the purpose of this article, the top five themes include representative participant data. 
Table 1: Final Themes With Unique Participants and Total Related Words

\begin{tabular}{lcc}
\hline & $\begin{array}{c}\text { Total unique } \\
\text { participants } \\
(N=20)\end{array}$ & $\begin{array}{c}\text { Total words related to } \\
\text { theme }\end{array}$ \\
\hline Mheme & 18 & 5,794 \\
Greater self-regulation & 17 & 6,585 \\
Commitment to the practice & 17 & 4,259 \\
Enhanced self-awareness & 17 & 7,199 \\
Improved work relationships & 16 & 5,233 \\
Greater inner calm and peace & 14 & 3,442 \\
Greater self-/other-empathy and compassion & 14 & 3,664 \\
Deeper listening and being present & 12 & 3,574 \\
Motivated by a personal/professional crisis & 11 & 1,495 \\
More tolerance for ambiguity and uncertainty & 11 & 3,594 \\
\hline
\end{tabular}

\section{Theme 1: More Integrated and Balanced Leadership}

Through the context of organizational life in work relationships, stressful situations, and high demands, 18 of 20 leaders experienced more integration in their approach to leadership as a result of their mindfulness practice. As one participant explained,

And you know, I feel like I work hard, I am responsible. There are times when I say, "okay, that is enough for today, shut the computer off because now I need my other time. If I don't have that, tomorrow is not going to be [a] great day because I am going to be tired or whatever." So having that wisdom to do that, which I could not do before. (Female small-business owner and former senior healthcare executive)

Thus, more integrated leadership style represented the first and most represented theme followed by greater self-regulation.

\section{Theme 2: Greater Self-Regulation}

In and through the context of life in general, and organizational life specifically, situations such as managing depression and anxiety without medication, interpersonal conflict, work stress, and working with and in bureaucratic systems, 17 of 20 leaders experienced greater self-regulation from their mindfulness practice. As highlighted by another participant,

So mindfulness training itself, it—so paying attention to what's happening in the moment, allows me to be, you know, to be nonreactive in situations, in challenging situations, that anybody that's worked especially in any sort of leadership position, [has] happen. (Male middle manager and scientist)

Similarly, 17 of 20 leaders experienced greater self-regulation from their mindfulness practice.

\section{Theme 3: Commitment to the Practice}

The continued cultivation of mindfulness through a consistent formal practice, informal practices (e.g., mindful eating), periodic retreats, being part of a mindfulness-oriented community, and other supportive practices were stated commitments expressed by 17 of the 20 leaders interviewed. A participant explained, 
I mean truly, I think there is an aspect of kind of like no turning back. I'm not going to go back to-no matter how hard the practice is or how hard it is to be very aware, I know the sort of pain and the feeling of loss and how difficult it is for the alternative, to kind of just rest in our comfort zones and not examine the way we do things. (Male middle manager in the health and wellness industry)

Likewise, this type of commitment to the practice was a theme for 17 of 20 interviewees.

\section{Theme 4: Enhanced Self-Awareness}

Through the context of organizational life that includes meetings, interactions with other stakeholders, interpersonal conflicts, and stressful tasks and timelines, 17 of 20 leaders experienced enhanced self-awareness as a developmental result of their mindfulness practice. As highlighted by another participant,

So, it has helped me to notice how I am in relationship and how I come across. It has helped me to continue to refine how I am with others so that I can work better with people. It has helped me to manage conflict with people when there is conflict, better. (Female middle manager in the personaldevelopment industry)

Similarly, 17 of 20 leaders experienced enhanced self-awareness as a developmental result of their mindfulness practice.

\section{Theme 5: Improved Work Relationships}

Through the context of work relationships, 16 of 20 leaders experienced improved work relationships as a developmental result of their mindfulness practice. One participant elaborated,

So the relationships become more collaborative. I think that invitations to be participating in things tend to increase because people see you as telling it like it is but doing it in a way that's not combative. So I think you'd have to look at each individual relationship, but I think that the relationships tend to grow. (Male senior manager with a Canadian-based hospital)

Likewise, 16 of 20 leaders experienced improved work relationships because of their mindfulness practice.

\section{Discussion}

The findings from this study are consistent with the growing body of literature on the developmental potential of mindfulness meditation. For example, the themes of greater self-regulation and selfawareness align with work by Karssiens, van der Linden, Wilderom, and Furtmueller (2014) who concluded that mindfulness training enhanced leaders' ability to recognize and govern physical sensations, emotions, thoughts, and nonproductive habitual patterns. Furthermore, Boyatzis and McKee (2013), Brown and Ryan, (2003), and Ruderman et al. (2014) support a potential correlation between mindfulness and self-awareness.

The themes of deeper listening, greater self/other empathy, and improved work relationships align with work by Boyatzis and McKee (2013), Goldman Schuyler (2010), and Wallace and Shapiro 
(2006). For example, Boyatzis and McKee (2013) proposed mindfulness training and practice often enhance the ability of leaders to resonant with stakeholders, thereby improving the quality of work relationships.

Finally, the themes of inner calm align with the work of Jha, Stanley, Kiyonaga, Wong, and Gelfand (2010) and Roche et al. (2014). For example, Jha et al. (2010) concluded that mindfulness practices helped foster positive moods in military personnel, and Roche et al. (2014) determined that mindfulness and an individual's positive psychological state might support the type of psychological resiliency leaders need to maintain mental well-being.

Three comprehensive categories represent the competencies associated with global leader effectiveness: perception management, relationship management, and self-management (Bird et al., 2010). Although the study's findings are not generalizable to all leaders, the findings align with these broad leadership competency categories identified by Bird et al. The findings also complement literature highlighted on vertical learning, which emphasized the need for leaders and organizations to consider vertical growth along with horizontal growth in their development plans and investments (e.g., Petrie, 2014, 2015).

Although some themes that emerged from the study (e.g., commitment to the practice), were not represented in the full literature review, they did not contradict the literature. However, the findings do help expand on the knowledge in the literature review, particularly in the potential of mindfulness meditation as a developmental technique for leaders and organizations. This developmental potential is congruent with the original purpose of mindfulness meditation, selfliberation or enlightenment.

\section{Implications for Social Change}

Mindfulness meditation is not new. It has roots in the ancient wisdom tradition of Buddhism. What is new, however, is the scale at which it is available. In the past, the techniques, practices, and teachings were only available to a select few, such as members of priestly classes. Today, they are available to anyone with access to the Internet. This mass availability of mindfulness meditation is unprecedented. Therefore, the potential implications are far reaching.

First, the implications for positive change on the individual level are promising. As evidenced by these findings and other studies, mindfulness meditation has transformative potential for individual leaders who regularly, consistently, and skillfully practice. Although one transformed leader may not be able to transform an entire organization, "transforming individuals through leader development efforts also transforms organizations" (Day, Zaccaro, \& Halpin, 2004, p. 11).

Whereas one transformed leader with greater self-awareness can make a positive difference in an organization, investment in mindfulness training for multiple leaders or leadership teams might transform entire organizations. In turn, although beyond the boundaries of this study, transformed organizations have the potential to transform societies and the world. Therefore, recommendations for practice include consideration of mindfulness meditation and other contemplative practices by leaders and organizational decision makers of leader development investments. However, mindfulness meditation is not a panacea or quick fix for leaders or organizations, nor is it an easy or pleasurable "do when you please" activity, as it also requires a long-term commitment to regular selfobservation and self-honesty, which includes facing the shadow sides, dark and golden, of the psyche.

As highlighted by Reddy and Srinivasan (2015), leaders and organizations must consider the goals of leadership development. If they desire vertical growth, they must initiate interventions that will 
facilitate such learning, which may require serious investigation of firmly held assumptions about leader development. Organizations cannot mandate vertical growth. However, they can invest in, offer, encourage, and support leaders in experimenting with mindfulness meditation and other contemplative practices when conditions are suitable (i.e., leader readiness, courage, and discipline).

\section{Recommendations}

Vast opportunities for future research exist. Possible areas for research include additional collection and analysis of first person data to determine if leaders' experiences consistently mirror findings of other clinical and nonclinical populations. If not, additional first person, leader-center ed studies could inform the selection of more precise assessment instruments for greater statistical insight of desirable leader capacities (e.g., EQ assessments).

Furthermore, developmental stage assessments such as sentence completion tests (e.g., Maturity Assessment Profile; Cook-Greuter, 2010), the Leadership Circle Profile (Anderson, 2006), and Subject-Object Interviews (Kegan \& Lahey, 2009) could be informative. In addition, organizational case studies that include observation, interviews, and historical performance data (financial and nonfinancial) analysis might prove illuminating. Moreover, research opportunities exist in longitudinal studies of leaders who make commitments to long-term regular mindfulness practices.

\section{Conclusion}

Humanity faces unprecedented challenges such as climate change, terrorism, and water scarcity (Guillén \& Ontiveros, 2012). Humanity's collective future is every capable adult's responsibility. However, those of us who serve in leadership positions have greater responsibility and opportunity to help solve our most pressing global challenges and midwife a positive future.

Currently, however, a gap exists between the demands of the global environment and the capacities of leaders to respond to challenges with innovative and collaborative action for a thriving Earth community. Consequently, leaders who yearn to contribute to real solutions will have to access more of their potential. Traditional ways of learning will not suffice. People must open their hearts and minds to practices that foster vertical learning, not with blind faith, but with genuine willingness to experience for themselves whether these practices make a real difference in their lives.

\section{References}

Anderson, D., \& Ackerman-Anderson, L. S. (2010). Beyond change management: How to achieve breakthrough results through conscious change leadership. San Francisco, CA: Pfeiffer.

Anderson, R. J. (2006). The leadership circle profile: Breakthrough leadership assessment technology. Industrial and Commercial Training, 38, 175-184. doi: $10.1108 / 00197850610671946$

Avolio, B. J., \& Hannah, S. T. (2008). Developmental readiness: Accelerating leader development. Consulting Psychology Journal: Practice and Research, 60, 331-347. doi:10.1037/10659293.60.4.331

Baron, C., \& Cayer, M. (2011). Fostering post-conventional consciousness in leaders: Why and how? Journal of Management Development, 30, 344-365. doi:10.1108/02621711111126828 
Bennis, W. G. (2009). On becoming a leader [Kindle version]. Retrieved from http://www.amazon.com/Becoming-Leader-W arren-Bennisebook/dp/B007MB5RA8/ref=sr_1_1_twi_kin_2?ie=UTF8\&qid=1458591599\&sr=8 $1 \&$ keywords=On+becoming + a+leader

Bird, A., Mendenhall, M., Stevens, M. J., \& Oddou, G. (2010). Defining the content domain of intercultural competence for global leaders. Journal of Managerial Psychology, 25, 810-828. doi: $10.1108 / 02683941011089107$

Bolden, R., \& Gosling, J. (2006). Leadership competencies: Time to change the tune? Leadership, 2, 147-163. doi:10.1177/1742715006062932

Boyatzis, R. E., \& McKee, A. (2013). Resonant leadership: Renewing yourself and connecting with others through mindfulness, hope, and compassion [E-book version]. Retrieved from https://play.google.com/stor e/books/details?id=etkqwO_Cd-EC

Brown, K. W., \& Ryan, R. M. (2003). The benefits of being present: Mindfulness and its role in psychological well-being. Journal of Personality and Social Psychology, 84, 822-848. doi:10.1037/0022-3514.84.4.822

Brown, K. W., Ryan, R. M., \& Creswell, J. D. (2007). Mindfulness: Theoretical foundations and evidence for its salutary effects. Psychological Inquiry, 18, 211-237. doi: $10.1080 / 10478400701598298$

Cook-Greuter, S. R. (2010). Postautonomous ego development. A study of its nature and measurement (Doctoral dissertation). Pacific Grove, CA: Integral.

Day, D. V. (2001). Leadership development: A review in context. The Leadership Quarterly, 11, 581613. doi:10.1016/S1048-9843(00)00061-8

Day, D. V., Harrison, M. M., \& Halpin, S. M. (2012). An integrative approach to leader development: Connecting adult development, identity, and expertise [E-book version]. Retrieved from https://play.google.com/stor e/books/details?id=JcN4pZOAFLAC

Day, D. V., Zaccaro, S. J., \& Halpin, S. M. (2004). Leader development for transforming organizations: Growing leaders for tomorrow. Mahwah, NJ: Lawrence Erlbaum.

Gelles, D. (2015). Mindful work: How meditation is changing business from the inside out. [Kindle version]. Retrieved from http://www.amazon.com/Mindful-Work-Meditation-ChangingBusiness-ebook/dp/B00LZ7GPH 4/ref=sr_1_1_twi_kin_2?ie=UTF8\&qid=1458591687\&sr=8 $1 \&$ keywords $=$ Mindful + work $\% 3 \mathrm{~A}+$ How + meditation + is + changing + bu sin ess + from + the + inside + out

Glomb, T. M., Duffy, M. K., Bono, J. E., \& Yang, T. (2011). Mindfulness at work. Research in Personnel and Human Resources Management, 30, 115-157. doi:10.1108/S07427301(2011)0000030005

Goldman Schuyler, K. G. (2010). Increasing leadership integrity through mind training and embodied learning. Consulting Psychology Journal: Practice and Research, 62, 21-38. doi:10.1037/a0018081

Goleman, D. (1988). The meditative mind: The varieties of meditative experience. New York, NY: G. P. Putnam's Sons.

Guillén, M. F., \& Ontiveros, B. E. (2012). Global turning points: Understanding the challenges for business in the 21st century. Retrieved from https://www.coursera.org/course/globaltrends 
Hezlett, S. A. (2008). Using multisource feedback to develop leaders: Applying theory and research to improve practice. Advances in Developing Human Resources, 10, 703-720. doi:10.1177/1523422308322271

Jha, A. P., Stanley, E. A., Kiyonaga, A., Wong, L., \& Gelfand, L. (2010). Examining the protective effects of mindfulness training on working memory capacity and affective experience. Emotion, 10, 54-64. doi:10.1037/a0018438

Joiner, B., \& Josephs, S. (2007). Developing agile leaders. Industrial and Commercial Training, 39, 1, 35-42. doi:10.1108/00197850710721381

Kabat-Zinn, J. (1994). Wherever you go, there you are: Mindfulness meditation in everyday life. New York, NY: Hyperion.

Karssiens, A. E. A., van der Linden, C., Wilderom, C. P. M., \& Furtmueller, E. (2014). Embodied mind knowledge in leadership practice: Creating space in patterned thoughts and behaviors. Journal of Management Inquiry, 23, 231-241. doi:10.1177/1056492613513501

Kegan, R., \& Lahey, L. L. (2009). Immunity to change: How to overcome it and unlock potential in yourself and your organization. Boston, MA: Harvard Business Press.

Kemeny, M. E., Foltz, C., Cavanagh, J. F., Cullen, M., Giese-Davis, J., Jennings, P., . . Ekman, P. (2012). Contemplative/emotion training reduces negative emotional behavior and promotes prosocial responses. Emotion, 12, 338-350. doi:10.1037/a0026118

Ligon, G. S. \& Hunter, S. T. (2010). Putting the development into experiential development. Industrial and Organizational Psychology, 3, 28-32. doi.org/10.1111/j.17549434.2009.01192.x

McCall, M. W. (2010). Recasting leadership development. Industrial and Organizational Psychology, 3, 3-19. doi:10.1111/j.1754-9434.2009.01189.x

McDermott, A., Kidney, R., \& Flood, P. (2011). Understanding leader development: Learning from leaders. Leadership \& Organization Development Journal, 32, 358-378. doi: $10.1108 / 01437731111134643$

Moustakas, C. E. (1994). Phenomenological research methods. Thousand Oaks, CA: Sage.

Murphy, S. E., \& Johnson, S. K. (2011). The benefits of a long-lens approach to leader development: Understanding the seeds of leadership. The Leadership Quarterly, 22, 459-470. doi:10.1016/j.leaqua.2011.04.004

Petrie, N. (2011). Future trends in leadership development. Retrieved from http://www .ccl.org/leadership/pdf/research/futureTrends.pdf

Petrie, N. (2014). Vertical leadership development: Part 1: Developing leaders for a complex world. Retrieved from http://insights.ccl.org/articles/white-paper/vertical-leadership-developm entpart-1-developing-lea ders-for-a-com plex-world/

Petrie, N. (2015). The how-to of vertical leadership development: Part 2: 30 experts, 3 conditions, and 15 approaches. Retrieved from http://www.ccl.org/leadership/research/sharing/VerticalLeadersPart2.as px

Petriglieri, G., Wood, J. D., \& Petriglieri, J. L. (2011). Up close and personal: Building foundations for leaders' development through the personalization of management learning. Academy of Management Learning \& Education, 10, 430-450. doi:10.5465/amle.2010.0032 
Rauzi, R. (2013, February 24). Tapping into the power of mindfulness: Companies are embracing meditation to train better leaders, one breath at a time. Retrieved from http://articles.latimes.com/2013/feb/23/busines s/la-fi-m editation-management $-20130224$

Reddy, C. M., \& Srinivasan, V. (2015). Dialogue on leadership development. IIMB Management Review, 27, 44-55. doi:10.1016/j.iimb.2015.02.001

Roche, M., Haar, J. M., \& Luthans, F. (2014). The role of mindfulness and psychological capital on the well-being of leaders. Journal of Occupational Health Psychology, 19, 476-489. doi:10.1037/a0037183

Ruderman, M. N., Clerkin, C., Connolly, C., \& Center for Creative Leadership. (2014). Leadership development beyond competencies moving to a holistic approach [White paper]. Retrieved from http://www.ccl.org/leadership/pdf/research/ leadershipdevelopmentcom petencies.pdf

Shapiro, S. L., Carlson, L. E., \& Kabat-Zinn, J. (2009). The art and science of mindfulness: Integrating mindfulness into psychology and the helping professions. Washington, DC: American Psychological Association.

Siegel, R. D. (2014). Lecture on groundbreaking mindfulness programs in the science of mindfulness [MP3]. Chantilly, VA: The Teaching Company.

Tan, C. M. (2012). Search inside yourself: The unexpected path to achieving success, happiness (and world peace) [Kindle version]. Retrieved from http://www.amazon.com/Search-InsideYourself-Unexpected-Achievingebook/dp/B0070XF474/ref=sr_1_1_twi_kin_2?ie=UTF8\& qid=1458591967\&sr=8 $1 \&$ keywords=Search+inside+yourself $\% 3 \mathrm{~A}+$ The + un ex pected + path + to + achieving + success $\% 2 \mathrm{C}$ +happiness+\%28and+world+peace $\% 29$

Torbert, W. R., \& Cook-Greuter, S. R. (2004). Action inquiry the secret of timely and transforming leadership [Kindle version]. Retrieved from http://www.amazon.com

Vazirani, N. (2010). Competencies and competency model: A brief overview of its development and application. SIES Journal of Management, 7,121-131.

Wallace, B. A., \& Shapiro, S. L. (2006). Mental balance and well-being: Building bridges between Buddhism and Western psychology. The American Psychologist, 61, 690-701. doi:10.1037/0003-066X.61.7.690

Weiss, D. S., \& Molinaro, V. (2010). The leadership gap: Building leadership capacity for competitive advantage. San Francisco, CA: Jossey-Bass.

The Journal of SocialChange, sponsored by Walden University, welcomes manuscripts focusing on interdisciplinary research in social change that improves the human condition and moves people, groups, organizations, cultures, and society toward a more positive future.

Walden University Publishing: http://www.publishing.waldenu.edu 